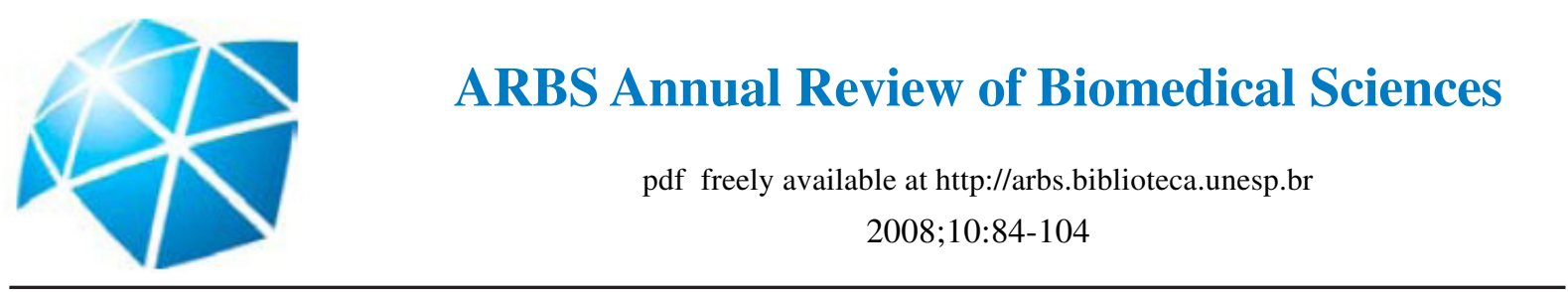

\title{
Attention and Emotion*
}

\section{Ram L P Vimal ${ }^{\dagger}$}

Vision Research Institute, Acton, MA, USA

Dristi Anusandhana Sansthana, A-60 Umed Park, Sola Road, Ahmedabad, Gujrat, INDIA

Dristi Anusandhana Sansthana, c/o NiceTech Computer Education Institute, Pendra, Bilaspur, C.G., INDIA

Dristi Anusandhana Sansthana, Sai Niwas, East of Hanuman Mandir, Betiahata, Gorakhpur, U.P., INDIA

Received: 21 January 2007; accepted 19 August 2008

Online on 25 August 2008

\section{Abstract}

Vimal RLP. Attention and Emotion. ARBS Annu Rev Biomed Sci 2008;10:84-104. Attention is central to many functions such as vision, emotion, reward, working memory and access awareness. However, it is not clear how attention interacts with emotion and how to separate them. We report that (1) Visual attention is a (reentrant) neural signal that enhances the feed-forward stimulus-related signal by modulating it. (2) Emotion is feeling related affective subjective experience; its neural correlate is amygdala-neural-net. (3) Attentional modulating signal could be in forward (bottom-up) direction from attentional 'source' such as thalamic reticular nucleus or in backward (feedback, top-down) direction from attentional 'source' such as fronto-parietal network. The 'targets' of attention may be fusiform gyrus for face recognition, amygdala for emotion, and 'nucleus accumbens, amygdala, sublenticular extended amygdala of the basal forebrain, hypothalamus, orbitofrontal cortex, and ventral tegmentum of the midbrain in humans' for reward system. (4) There are five aspects of attention reflected in five attentional tasks: sustained, covert, divided, selective, and switching attention. The basic attention mechanism may be similar in all attentional tasks. (5) Selective attention plays major role in facial emotion. (6) Attention potentiates the processing of face recognition, sharpens the discriminations of facial emotions, and increases the sensitivity of reward. Emotional salience of the stimuli can regulate attention. (7) It is possible to separate attentional areas from emotion related areas using fMRI. (8) A dual-aspect framework can address the explanatory gap (how emotional subjective experiences can arise in emotion related neural-net). In conclusion, attention modulates emotion and related systems such as face recognition and reward.

(C) by São Paulo State University - ISSN 1806-8774

Keywords: attention, face recognition, fusiform gyrus, emotion and emotional salience, amygdale, reward, fMRI

*This work was partly supported by VP-Research Foundation Trust, James T Beran Revocable Trust, and Vision Research Institute research Fund.

Correspondence

Ram LP Vimal. Vision Research Institute; 428 Great Road, Suite 11, Acton, MA 01720, USA. E-mail: rlpvimal@yahoo.co.in; Website: http://www.geocities.com/rlpvimal/ 


\section{Table of Contents}

1. Introduction

2. Attention

2.1. Definition

2.2. Forms of attention

2.3. Relation between five forms of attention

3. Effects of Attention on Emotion and Related Systems

3.1. Emotion

3.2. Face recognition

3.3. Reward system

3.4. Interaction between attention, emotion, and related systems

3.5. A framework to address the explanatory gap for emotional subjective experiences 3.5.1. The PE-SE framework

3.5.2. Formation of neural-net and the emergence of SE: neural Darwinism

4. Future Directions

5. Concluding Remarks

6. Acknowledgments

7. Competing Interests Statement

8. References

\section{Introduction}

Attention is central to both basic and clinical researches and plays important role in vision, perception, emotion, reward, memory, awareness/consciousness ${ }^{1}$, subjective experiences, and action selection (Bushnell et al., 2000; Kanwisher \& Wojciulik, 2000; Vuilleumier et al., 2001; Pessoa et al., 2002; Vasterling et al., 2002; Hamker, 2004; Levinoff et al., 2004; Wager et al., 2004; Vuilleumier, 2005; Vuilleumier \& Driver, 2007). Attention is essential to the construction of every subjective experience (Kanwisher \& Wojciulik, 2000), including emotions such as happiness, sadness, and so on

\footnotetext{
${ }^{1}$ From my unpublished work, "In materialism, consciousness is defined as (a) a multidimensional process that "emerges from interactions of the brain, the body, and the environment", and (b) "the result of dynamic interactions among widely distributed groups of neurons" (Edelman, 2003). In general, the following meanings are attributed to the term 'consciousness': (1) Self (subjective or first person experience of subject) or self-awareness denoted by 'I', (2) subjective experience (SEs) of objects or qualia, (3) proto-experiences (PEs), (4) SEs related to sensations, perceptions, moods, emotions, dreams, and so on, (5) access and phenomenal awareness, (6) thought, (7) free will, (8) attention, (9) phenomenal time and phenomenal space, (10) processing of SE, (11) thought processing, (12) cognition including memory, inner speech, imagination, behavior (including adaptive activity), intentionality, and language, (13) initiation of activities, and/or other cognitive processing, (14) thrownness in the world, (15) interpreter of sensory signals, (16) act of processing and conceptualization of information, (17) self-organization, (18) neural-nets using ineffable phenomenal properties to represent information, (19) responsive to the environment, and (20) the interaction between dynamic physical entities for information processing in self-organizing manner and panexperientialism, (21) consciousness as physical processes, (22) stream of intentional information, (23) reflective awareness, such as perception, thought, and volition, (24) paradoxical awareness or awareness without being aware, such as subliminal perception, implicit memory, blindsight, and hypnotic analgesia, (25) awareness of awareness, (26) intuitive awareness, (27) intentional entity in western perspective, (28) non-intentional entity in eastern perspective, (29) awareness of unity and continuity in one's awareness or stream of awareness, and (30) awareness-as-such or pure awareness of yogins, such as during the unification of SE of observer, SE of observed objects, and the processing of SEs at 'samadhi' state. These meanings (or aspects) are not necessarily different or independent; rather some of them might be overlapping. The aspects (28)-(30) are eastern perspectives. In non-materialistic non-reductive views (such as dualism, panpsychism, proto-panpsychism, experientialism, and dualaspect views), consciousness is an irreducible fundamental non-material mental entity, even if it is closely associated with material processes. In dual-aspect PE-SE framework (Vimal, 2008), the SE-related aspects (perhaps aspects 1-5, also possibly 7-9, 23-26, and 28-30) of consciousness are irreducible fundamental mental aspects of entities and the material-related aspects (perhaps aspects 10-22 and 27) of consciousness are material-aspects of entities (and hence they are processes). We suggest that it would be more precise if we specify which specific aspect(s) of consciousness we are addressing, rather than using the term consciousness without defining it."
} 
that are the feeling related affective subjective experiences (Bruzzo \& Vimal, 2007; Vimal, 2007, 2008; MacGregor \& Vimal, 2008; Vimal \& Davia, 2008). The above roles of attention are not only significant because attention likely modulates their all aspects of processing but also because impaired mechanisms of attention are fundamental aspects of a variety of human illness states. Psychophysical studies such as ours on visual mechanisms (Vimal, 1997, 1998a,b, 2000, 2002a,b) were performed with high degree of attention; however, a research with lower degree of attention is also needed to elucidate the effects of attention. External physical characteristics of visual stimuli are processed by the abstract psychophysical tuned mechanisms of color (Vimal, 1997, 1998a,b, 2002a) and luminance (Wilson et al., 1983; Lehky, 1985; Vimal, 2002b) channels of the human visual system to provide sensation and perception. It could be argued that attention sharpens these tuned mechanisms. For access (reportable) awareness, such as reporting face recognition and its emotional experience, attention is essential. For phenomenal visual awareness (Lamme, 2003), lower visual areas including fusiform gyrus (GF) may be involved but attention and reward system may not be activated. Thus, gaining a better understanding of the role of attention in visual processing, emotion, reward, working memory and awareness offers the direct opportunity to understand better visual perception and emotional experience while also informing us about attentional alterations in disease states. Although there have been several excellent reviews on attention and emotion [such as Pessoa et al. (2002), Vuilleumier (2005), Vuilleumier \& Driver (2007)], there is still some unresolved problems and missing information. For example, the effect of various forms of attention on emotion (especially facial emotion) needs further elaboration and a framework for addressing the famous 'explanatory gap' (Levine, 1983; Chalmers, 1995) in materialism (how precisely emotional subjective experiences arise in brain) is missing. In this article, our goals are (i) to review and elucidate the effects of attention on emotion and closely related systems such as face recognition and reward and (ii) to concisely discuss and extend the framework (Vimal, 2008) to address the 'explanatory gap' for emotional subjective experiences where attention and emotion play important role.

In Section 2, we concisely define attention, discuss the five forms of attention tasks, and their relation to each other. The definition of emotion, effects of attention in face recognition, emotion, and reward, and the framework to address the 'explanatory gap' for emotional subjective experiences are concisely discussed in Section 3. Future research projects are suggested in Section 4. Finally, the conclusion synthesizes our main thesis.

\section{Attention}

\subsection{Definition}

Satisfactory definition of 'attention' is still awaited. However, the following definitions are found in literature: (i) James in 1890 defined attention as, It [attention] is the taking possession by the mind, in clear and vivid form, of one out of what seem several simultaneously possible objects or trains of thought. Focalization, concentration, of consciousness are of its essence. It implies withdrawal from some things in order to deal effectively with others, and is a condition which has a real opposite in the confused, dazed, scatterbrained state (James, 1890). This definition is mostly for selective attention, whereas there are at the least five forms of attention tasks (sustained, covert, divided, selective, and switching attention: see below). (ii) Attention is a mental activity that describes multiple cognitive phenomena (Levinoff et al., 2004). (iii) Attention is a mechanism that controls (selects) which brain processes enter access awareness and which do not (Fell, 2004; Kranczioch et al., 2005). (iv) Attention is an emergent phenomenon that arises from reentry and slow competitive interactions (Desimone \& Duncan, 1995; Hamker, 2004). For example, "Prior to an eye movement, a spatially organized reentry

\footnotetext{
${ }^{2}$ The color area 'V8/V4/VO' refers to V8 of Tootell-group (Hadjikhani et al.,, 1998; Tootell et al., 2003), V4 of Zeki-group (Bartels \& Zeki, 2000), and VO of Wandell-group (Wandell, 1999); they are the same human color area (Tootell et al., 2003). IT is inferior temporal cortex related to object recognition. GF is fusiform gyrus face area. V5 is visual area 5, MT is middle temporal visual area, and MST is middle superior temporal area; they are related to motion.
} 
from occulomotor centers, specifically the movement cells of the frontal eye field, occurs and modulates the gain of V4 and IT cells" (Hamker, 2005, p. 431). (v) Attention can be considered as the modulation of neural activity, so that the processing of some information is enhanced whereas other is inhibited. This definition can address how stimulus-driven (exogenous) vs. goal-directed (endogenous) sources of attention plays out in various types of attention tasks. In other words, neurophysiologically, visual attention can be defined as a neural signal that modulates the main feed forward pathways (ventral pathway: retina $\rightarrow \mathrm{LGN} \leftrightarrow \mathrm{V} 1 \leftrightarrow \mathrm{V} 2 \leftrightarrow{ }^{\prime} \mathrm{V} 8 / \mathrm{V} 4 / \mathrm{VO}^{\prime} \leftrightarrow \mathrm{IT} \leftrightarrow \mathrm{GF}$ and dorsal pathway: retina $\rightarrow$ LGN $\leftrightarrow \mathrm{V} 1 \leftrightarrow \mathrm{V} 2 \leftrightarrow \mathrm{V} 5 / \mathrm{MT} / \mathrm{MST} \leftrightarrow \mathrm{IPL} /$ parietal cortex) (Treue, 2001). ${ }^{2}$

\subsection{Forms of attention}

The concept of attention is heterogeneous, and different definitions have been (and can be) used, depending on more precisely which attention functions are under scrutiny. As a consequence, I will first concisely summarize the various forms of attention, and then I will focus mostly on selective attention because it has higher relevance to emotion processing. Visual attention tasks can be grouped into five forms (Bushnell et al., 2000): First, in foveal short-sustained, long-sustained, and vigilance attention tasks, subjects attend the target foveally for short time-period (1-30 s) in short-sustained attention (Buchel \& Friston, 1997; Vimal, 1998b; Festman \& Ahissar, 2003), prolonged period of time (seconds to minutes) in long-sustained attention, and very long time-period (minutes to hours) in vigilance attention (Parasuraman, 1984; Coull, 1998). Second, in covert attention task, subjects attend to peripheral stimulus without moving eyes while fixating foveally. It involves attentional orientation: attention is directed to a particular stimulus or location. In sustained covert attention (Nakayama \& Mackeben, 1989; Cheal \& Lyon, 1991; Corbetta \& Shulman, 2002; Ling \& Carrasco, 2005), information is voluntarily monitored at a given location; it is endogenous or top-down orienting signal and is driven in about 300 ms; it operates via contrast gain [and also via response gain in dual-task (Huang \& Dobkins, 2005)]. Whereas transient covert attention (Nakayama \& Mackeben, 1989; Cheal \& Lyon, 1991; Corbetta \& Shulman, 2002; Ling \& Carrasco, 2005) corresponds to a faster involuntary capture of attention to a location where sudden salient stimulation has occurred; it is exogenous or bottom-up orienting signal and is driven in about $100 \mathrm{~ms}$; it operates via a mixture of response gain and contrast gain (Ling \& Carrasco, 2005). Third, in divided attention task, subjects divide their attention between two (or more) different stimuli. Here, attentional resources are distributed between two (or more) competing inputs at the same time (Coull, 1998). Fourth, in selective (or focused) attention task, subjects attend the target and ignore distracters (Vandenberghe et al., 1996; Barrett et al., 2003; Pinault, 2004). The modulatory effects of visual selective attention task occur at the sensory level (striate and extrastriate cortex) in addition to higher decision stages (Hawkins et al., 1990; Somers et al. 1999; Slotnick et al., 2003). Selective attention enhances activation in the cortical regions related to the attended stimulus and diminishes activation elsewhere (Somers et al., 1999). Fifth, in switching attention task, subjects switch attention to another task by disengaging attention from the first task and engaging to the second one. Here, flexible thought processes are required (Smith et al., 1998; Barrett et al., 2003). In general, switching attention task is associated with the preparation of eye-movement, which involves premotor processing (Kustov \& Robinson, 1996). Switching tasks, used by various investigators, can be classified into 5 types (Wager et al., 2004): (a) location switching: switching of attention between two spatial locations; (b) attribute switching: switching of attention from one feature of an object to another (e.g., from shape to color); (c) rule switching: switching of attention from one rule (press key A when you saw an X, and key B when you saw a Y) to reverse rule (key B for X, and A for Y); (d) object switching: switching of attention between two stimuli or relevant objects; and (e) task switching: switching of attention between two responses or two operations that are applied to stimuli; for example, switching attention from making an odd/even judgment of a number to making a vowel/consonant judgment on

letter-number pairs (Rogers \& Monsell, 1995). Furthermore, the term spatial attention is used in literature for the attention related to space (such as location-based selective attention) (Treue, 2003) but it may involve other forms of attention. 


\subsection{Relation between five forms of attention}

All five forms of attention modulate the main feed forward stimulus dependent information processing, which may be emotionally loaded. In both covert and overt attentions, preparation of eyemovement that involves premotor processing is needed, but eye is moved only in overt attention, such as in location switching and selective attention in visual search.

\section{Effects of Attention on Emotion and Related Systems}

\subsection{Emotion}

In general, "An emotion is a mental and physiological state associated with a wide variety of feelings, thoughts, and behaviours ... many researchers distinguish feeling and emotion, where feeling refers to the subjective experience of the emotion. Some believe that emotions can occur unconsciously, and hence that emotion is a more general phenomenon than its subjective feeling" [http://en.wikipedia.org/ wiki/Emotion; see also references therein, such as Lazarus (1991), Damasio (1999), Damasio et al. (2000) and Scherer (2005)]. In this article, we define emotion as feeling related affective subjective experience (SE) or first person experience, such as happiness, sadness, and so on (Bruzzo \& Vimal, 2007; MacGregor \& Vimal, 2008; Vimal, 2008; Vimal \& Davia, 2008). Furthermore, some of the basic emotions are amusement, anger, contempt, contentment, disgust, embarrassment, excitement, fear, guilt, pride in achievement, relief, sadness/distress, satisfaction, sensory pleasure, and shame; affective phenomena may include guilt, romantic or parental love and hate, grief, and jealousy; affective personality traits may include hostility (Ekman, 1992, 1993, 1999, 2003). One could argue that SE happiness is related to amusement, contentment, excitement, pride in achievement, satisfaction, and/or sensory pleasure.

In addition, the neural correlate of emotions may involve amygdala-neural-net (composed of all relevant neurons and interactions in the brain) and ionic activities in it. For example, the amygdala is a part of the system that is evolved for the rapid and reliable identification of individuals from their faces (Rolls, 1984, 1985, 1991; Leonard et al. 1985; Sander et al., 2005; Carvajal et al., 2007; Britton et al., 2008; Monk et al., 2008). Moreover, sodium, potassium, chlorine, calcium ionic activities (such as in NMDA-receptors (Pereira Jr., 2007a,b; Pereira Jr. \& Furlan, 2007a,b) are involved in the interaction between 'the emotional stimulus dependent feedforward neural signals that carry emotion related neuralproto-experiences' and 'the feedback fronto-parietal attentional signals' in the amygdala-neural-net. Here subject's subjective experiences such as happiness, sadness, and so on are emerged during this interaction perhaps either by matching and selection process or by the chaotic/random process of selforganization (Bruzzo \& Vimal, 2007; Vimal, 2007, 2008; MacGregor \& Vimal, 2008; Vimal \& Davia, 2008)

Furthermore, we elaborate amygdala system as follows. Amygdala ${ }^{3}$ (a) receives input signals from frontal cortex, hypothalamus, hippocampus, sensory cortex, and thalamus, and (b) sends output signals to frontal cortex, hypothalamus, basal ganglia, and midbrain. Amygdala can be divided into at least 5 main regions (the lateral, basal, accessory basal, central and the medial nuclei), which can be further divided into subnuclei (Amaral et al. 1992; Pitkanen, 2000). Our focus is on vision (face recognition), attention, and emotion. The caudal part of lateral nucleus receives signals from visual areas such as IT (inferior temporal area) for face and object recognition (Pitkanen, 2000). The basal nucleus and the accessory basal nucleus receive inputs from the lateral nucleus and can be seen as intermediate processing stages (Amaral et al., 1992). The central, medial, and basal nuclei are the main output region of the amygdala.

The three types of input signals to the amygdala are (i) signals that code parts of the current sensory situation (such as 'What am I looking at?'), (ii) signals that code innate significance (such as the value of a stimulus: 'Is it appetitive or aversive? Does it present a threat? Is it a potential mate?'), and (iii) signals that informs the amygdala of the current motivational state of the organism (such as

${ }^{3}$ Information related to Amygdala is partly obtained from www.lucs.lu.se/People/Jan.Moren/Kap2.ps. 
'Am I hungry, satiated, or sexually aroused?'). These early inputs may allow the amygdala to generate fast emotional responses and prepare the organism for responses related to 'fight or flight' (Gray, 1995; LeDoux, 1996). This initial reaction can later be modulated by the higher sensory areas. Alternatively, these signals can prepare the emotional system to process more efficiently the detailed information soon to arrive from the sensory areas. The amygdala receives input from hippocampus that is involved in spatial navigation, long-term memory, and contextual representations.

Two kinds of outputs of amygdala to the sensory cortices are (i) that used for priming sensory stimuli as part of an attentional system (Rolls, 1999), and (ii) that used for memory consolidation, where the emotional evaluation triggers the storing of long-term memories in, for example, the visual cortex (Cahill \& McGaugh, 1998; Tabert et al., 2001). Emotional reactions releases stress hormones (such as cortisol and adrenaline (LeDoux, 1995) that modulate memory consolidation, which involves basolateral amygdala (Roozendaal et al., 1998). The medial, central and anterior cortical nuclei of the amygdala send output signals to the lateral hypothalamus, which may produce emotional reactions and motivation (Rosenzweig \& Leiman, 1982).

Amygdala projects to prefrontal cortex (Rolls, 1995), which sends feedback signals to the lateral, basal and accessory basal nuclei of amygdala (Rolls, 1995; LeDoux, 1996; Pitkanen, 2000). Prefrontal cortex is involved in the interrelated functions such as working memory, preparatory set and inhibitory control (Fuster, 1997). Working memory stores a representation of current events and actions and the recent past. A preparatory set (or motor attention) primes the areas involved in the anticipation of awaiting action. Inhibitory control selectively inhibits inappropriate areas for the current situation. Amygdala is involved in the initial learning of an emotional response, whereas the orbitofrontal cortex is involved in the extinction by inhibiting earlier established connections when they are no longer appropriate (Rolls, 1995). Ventromedial prefrontal (VLPFC) cortex is involved in the anticipation of future reward or punishment, and dorsolateral prefrontal (DLPFC) cortex is involved in working memory to sustain emotional reactions over longer times (Davidson \& Irwin, 1999).

Amygdala system combines the input from (a) neurons in the temporal cortices that respond to face specific features (such as eyes, hair, or mouths) (Perrett et al. 1982), (b) temporal cortex neurons conveying information about facial expression (Hasselmo et al. 1989), and (c) other temporal regions involved with visual information processing (Aggleton et al. 1980). The human amygdala $\left(\sim 5.5 \mathrm{~cm}^{3}\right)$ (Filipek et al., 1994) responds preferentially to emotional faces (fearful or happy versus neutral faces) and rapidly ( 1 $\mathrm{min}$ ) habituates to them, however fusiform gyrus does not show this effect (Breiter $e t$ al., 1996).

\subsection{Face recognition}

Emotion system is closely related to face recognition system. Face recognition and complex feature detection involves Brodman area 37/19 in the fusiform gyrus (GF) (George et al., 1993; Sergent et al., 1994; Andreasen et al., 1996; Puce et al., 1996; Kanwisher et al., 1997; Haxby et al., 2002), which is a part of the ventral processing stream for visual information (Tootell et al., 1995). As discussed in (Breiter et al., 1996), the activation of face area in the 'fearful (or happy) versus neutral face' condition could be due to (a) modulation via back projections from other regions such as the amygdala (Amaral $e t$ al., 1992), (b) increased attention to emotional stimuli, or (c) regional processing of facial expression, consistent with animal electrophysiology (Rolls, 1991). The amygdala system for emotion, fusiform gyrus (GF) system for face recognition, and the frontal cortex for attention are linked. For example, the fusiform-amygdala is a system (projecting from the temporal cortex to amygdala) for the evaluation of faces and their emotional valence. In addition, attention signals from frontal cortex may potentiate the face recognition signal in GF (Wojciulik et al., 1998; Aharon et al., 2001). However, in a divided attention task (with near-absence of peripheral attention), subjects were able to discriminate the gender of peripheral faces with high performance whereas their performance of color discrimination (peripheral red-green vs. green-red disk) was very low (Reddy et al., 2004). Fusiform gyrus (GF) for face recognition is at higher level in ventral pathway than 'V4/V8/VO' and/or IT where red-green vs. green-red discrimination is performed. In other words, the effect of attention is less at GF level than that at 'V4/ V8/VO' level in their dual-task paradigm. Furthermore, it is postulated that attention is necessary for 
access (reportable) awareness but not for phenomenal awareness (Lamme, 2003). Thus, phenomenal awareness could also be associated with higher stages of ventral system. Further research is needed.

The accessory basal amygdaloid nucleus (Leonard et al., 1985) and face recognition areas in the inferior temporal cortex (IT and GF) react to certain facial expression (Perrett et al., 1992) and interact with each other. In addition, amygdala damaged patients cannot recognize facial expressions of fear, but can recognize other emotional expressions (Adolphs et al., 1996; Broks et al., 1998). The amygdala damage (a) impairs emotional memory for the gist but not for the details of complex stimuli (Adolphs et al., 2005), and (b) impairs the recognition of facial expressions of fear but not other emotional expressions (Adolphs et al., 1996; Broks et al., 1998).

\subsection{Reward system}

Emotion and reward systems are closely related; for example, amygdala is involved in both emotion and reward systems. The essential operations for motivation to produce behavior are: (i) selection of salient goal-objects, which involves selective attention system, (ii) compilation of goal-object information, and (iii) determination of concrete plans for securing goal-objects (Breiter \& Rosen, 1999). The compilation involves: (a) feature detection and other perceptual processing relevant to reward, (b) valuation of goal-object to determine its motivational salience, and (c) extraction of incidence and temporal data (Breiter \& Rosen, 1999). The motivational salience of goal objects is set by the dopaminergic neurons (Robinson \& Berridge, 1993). Amygdala is involved in orienting to and remembering affectively salient stimuli (Everitt et al., 1991; LeDoux, 1992; Hatfield et al., 1996). The nucleus accumbens/subcallosal cortex (NAc/SCC) is strongly interlinked to the amygdala (Yim \& Mogenson, 1982; Russchen et al., 1985; Amaral et al., 1992), which forms stimulus-reward associations (Spiegler \& Mishkin, 1981; Gaffan \& Harrison, 1988) and their effects on behavior (Cador et al. 1989). These may serve the attentional modulation of perception (Rolls, 1991; Breiter et al., 1996; Gallagher \& Chiba, 1996) needed for motivation. The perception of beauty may be innate (Langlois et al. 1991; Slater et al., 1998) and universal across race and culture (Jones \& Hill, 1993; Perrett et al., 1994; Cunningham et al., 1995). According to Shakespeare, Beauty is in the eyes of beholder. Although money and beautiful faces can both stimulate motivated behaviors, money cannot stimulate aesthetic evaluations (Aharon et al., 2001). Beautiful faces may elicit both reward and aesthetic evaluations, each leading to different patterns of neural activity (Aharon et al., 2001). Perception of beauty may overlap with desire (Kant, 1960) because it is not easy to dissociate reward from aesthetic effects with faces (Aharon et al., 2001). The sublenticular extended amygdala (SLEA) of the basal forebrain, orbitofrontal cortex (GOb), and ventral tegmentum (VT) of the midbrain may be associated with the general effect of beauty (Aharon et al., 2001). These results are consistent with predictions of the motivational salience (Berridge, 1996, 2000; Berridge \& Robinson, 2003), which entails 'wanting', but not 'liking', in terms of meso-accumbens dopaminergic function (Wyvell \& Berridge, 2000; Gur et al., 2002). The six brain regions involved in reward function are the NAc, amygdala, SLEA of the basal forebrain, hypothalamus, GOb, and VT of the midbrain in humans ( Delgado et al., 2000; Elliott et al., 2000; Knutson et al., 2000; Aharon et al., 2001; Breiter et al., 2001). Attention may enhance the sensitivity of reward system; this needs further research.

\subsection{Interaction between attention, emotion, and related systems}

There are several reasons for exploring the interaction between emotion and attention. One reason is that a pure information-processing perspective on attention fails to capture the obvious fact that our attention is regulated by the emotional salience of the stimuli, which might be a function of the stimuli and individual differences in what stimuli signify. The other aspect is that different levels of attention may affect emotional experiences differently. It would be interesting to address (a) specific aspects of emotions, such as under what contexts attention to emotional stimuli lead to enhanced or impaired performance or information processing and (b) the neurobiology of emotion-attention interactions.

Emotional system can contribute to attention. For example, when something emotionally significant is detected, subjects attend to the stimulus. The feedback signals from the amygdala to the 
sensory cortices may be involved in (a) directing attention to stimuli that are relevant to the current emotional and motivational state (Holland \& Gallagher, 1999), (b) biasing or priming cortical processing with the current emotional state (Amaral et al., 1992; LeDoux, 1996), and (c) the facilitation of memory creation for emotional stimuli. The amygdala connects to all levels of visual processing, including inferiotemporal area for the highest level of visual analysis (Rolls \& Treves, 1998).

The neural mechanism for modulating attention, on the basis of emotional cues, is different from that for modulating motivational value of cues in reward conditioning (Gallagher \& Holland, 1994; Gallagher, 2004). For example, the amygdala central nucleus function (related to the regulation of attention toward rewarding stimuli) can be dissociated from the basolateral nucleus function (related to the acquisition of cue value during conditioning) (Hatfield et al., 1996). The amygdala habituates rapidly to emotional stimuli and is concurrently activated with primary perceptual cortex (such as GF) to facial expression. This is consistent with the human amygdala that rapidly evaluates emotional valence and then modulates the GF-activity (via back projections) to enhance attention to emotional stimuli (Breiter et al., 1996). Since attention modulates BOLD signal in the GF that interacts with amygdala (Wojciulik et al., 1998), it is possible to evaluate variable attention to emotional and reward related facial stimuli. The interaction of identity (face recognition) in emotion processing is bi-directional; i.e. emotions may interfere in identity processing and vice-versa (Baudouin et al., 2002).

The processing of facial recognition and face emotion could be independent and parallel (Bruce \& Young, 1986; Nachson, 1995) under certain conditions as in the following studies. First, several psychological studies have shown that recognition or matching of facial emotion is not influenced by face familiarity (Bruce, 1986; Young et al., 1986; Campbell et al., 1996) and the recognition or matching of facial identity is not influenced by facial emotion (Bruce, 1982; Young et al., 1986). Second, neuropsychological studies suggested a dissociation between face recognition and facial emotion processing (Young \& Bruce, 1991; Young, 1992, 1998). Finally, physiological studies in primates and functional neuroimaging in humans showed that these two kinds of information are processed by different parts of the brain (Hasselmo et al., 1989; Sergent et al., 1994). Selective attention to one dimension implies that the variation of the second dimension does not interfere with correct classification (Baudouin et al., 2002). On the other hand, more recent findings suggest that face recognition and emotion processing interact under some conditions as in the following reports (Sansone \& Tiberghien, 1994; Schweinberger \& Soukup, 1998; Schweinberger et al., 1999). First, it takes more time to recognize the same emotion in different faces and to classify faces based on the emotion criterion while extracting the emotion from identity (Schweinberger \& Soukup, 1998; Schweinberger et al., 1999). Second, selective attention is required to process the emotional content of faces (Pessoa et al., 2002), which can play an important role in dissociating facial emotion from facial identity (face recognition). Selective attention is required to process the emotional content of faces (Pessoa et al., 2002). Attention signals from medial prefrontal cortex (Geday et al.,2003; Small et al., 2003; Shin et al., 2005) may potentiate emotion discrimination signal in amygdala. A hypothesis is that selective attention contributes in addressing the controversy over independence vs. interaction between face recognition and facial emotion.

The presence of affectively arousing stimuli enhances the switching of attention to a given hemifield (Stormark \& Hugdahl, 1996). Attention to emotional faces leads to affective modulation of the BOLD-response (Pessoa et al., 2002). Fronto-parietal attention network is involved in emotion perception and motivated attention (Moratti et al., 2004). Attention signals from frontal cortex may potentiate the face recognition signal in GF (Wojciulik et al., 1998; Aharon et al., 2001); and attention signals from medial prefrontal cortex (Geday et al., 2003; Small et al., 2003; Shin et al., 2005) may potentiate emotion discrimination signal in amygdala. Affectively arousing stimuli automatically draw attention, and emotion increases the facilitation effect of spatial attention and vice-versa (Keil et al., 2005), which is consistent with attention-emotion interaction hypothesis that can be tested further.

\subsection{A framework to address the explanatory gap for emotional subjective experiences}

According to materialism, subjective experiences (SEs) somehow emerge in neural-nets. This hypothesis leads to the famous 'explanatory gap' (Levine, 1983; Chalmers, 1995); for example, how 
can mental entities, such as emotional subjective experiences happiness, sadness, painfulness and so on can emerge from non-experiential matter such as emotion related neural-net? This is Type-1 explanatory gap. In Vimal (2008), we have proposed a relevant general framework for all types of SEs; here we will extend this framework to focus on emotional SEs. Before proceeding further, we need to define some terms. For example, proto-experiences (PEs) are those experiences that are not 'expressed-SEs'. Expressed-SEs are those experiences that satisfy the essential ingredients of SE (such as wakefulness, attention, reentry, working memory, stimulus above threshold), and that are expressed (i.e., that are not latent or covert or unexpressed).

\subsubsection{The PE-SE framework}

The problems of materialism and dualism, and the concise description of the PE-SE framework are as follows, "Deterministic reductive monism [materialism: unable to explain how SEs emerge from matter] and non-reductive substance dualism [association or mind-brain interaction problem, problem of mental causation, 'Zombie' problem and 'Ghost' problem: (Eerikäinen, 2000)] are two opposite views for consciousness and both have serious problems. An alternative view is needed. For this, we hypothesize that strings or elementary particles (fermions and bosons) have two aspects: (i) elemental proto-experiences (PEs) as phenomenal [mental] aspect and (ii) mass, charge, and spin as material aspect. Elemental PEs are hypothesized to be the properties of elementary particles and their interactions, which are composed [or a group] of irreducible fundamental subjective experiences (SEs)/PEs that are in superimposed form in elementary particles and in their interactions. Since SEs/PEs are superimposed, elementary particles are not specific to any SE/PE; they (and all inert matter) are carriers of SEs/PEs, and hence appear as non-experiential material entities." (Vimal, 2008, p. 49).

The PE-SE framework is further elaborated as, "Furthermore, our hypothesis is that matter and associated elemental PEs co-evolved and co-developed into neural-nets and associated neural-net PEs (neural Darwinism), respectively. The signals related to neural PEs interact in a neural-net and neuralnet PEs emerges from random process of self-organization. The neural-net PEs are a set of SEs embedded [and stored as memory traces] in the neural-net by a non-computational or non-algorithmic process. The non-specificity of elementary particles is transformed into the specificity of neural-nets by neural Darwinism." (Vimal, 2008, p. 49). For example, a specific SE happiness is selected out of embedded emotion related neural-net PEs in emotion related amygdala-neural-net when it is activated either by external happiness-related stimulus (say 'red rose') or by relevant internal signals such as that from memory.

In addition, "The specificity of SEs emerges when feedforward and feedback signal interacts in the neuropil and are dependent on wakefulness (i.e., activation) attention, re-entry between neural populations, working memory, stimulus at above threshold, and neural net PE signals. This PE-SE framework integrates reductive and non-reductive views, complements the existing models, bridges the explanatory gaps, and minimizes the problem of causation." (Vimal, 2008, p. 49).

The matching and selection of a specific SE in PE-SE framework is concisely described as, "the [matching and] selection process could simply be accomplished classically by the signal due to external stimulus, which is capable of activating the related embedded memory trace (i.e., the specific neural-net PE) in the relevant neural-net as the specific SE. Alternatively, orchestrated objective reduction (Orch OR) model (Hameroff \& Penrose, 1998), based on quantum coherence in dendritic microtubulenetwork (Engel et al., 2007), can also be used for the selection of the specific SE out of many neural-net PEs (embedded in microtubule-network) by collapsing many states (or PEs) into a specific one (SE) depending on the stimulus. The neural-net PEs embedded in neural-nets can be considered as neuralcorrelates of Penrose Platonic values encoded in fundamental space-time geometry (Hameroff, 2007), however, this mechanism is not clear." (Vimal, 2008, p. 57-8).

Our hypothesis is that neural-net-PEs are a set of subjective experiences (SEs) embedded in neural-nets. It is based on a framework that consists of four hypotheses (co-evolution and co-development of mind and brain, internal-representation, sensorimotor interaction, and dual-aspect model) that lead to structural and functional coherence between mind and brain, and bridge the explanatory gap (Vimal, 2008). One could argue that SEs are emerged entities from neural-nets; however, these material entities 
must have some trace of mental entities (such as elemental PEs). Therefore, matter must have associated elemental PEs.

Under deep anesthesia or deep sleep, we do not have signals for wakefulness and attention; therefore, we do not have SEs even though our neural-nets have signals related to reentry, memory, and PEs. In dreams, SEs are endogenously generated, which are different from SEs during wakefulness. Phosphenes (such as electrical stimulation, trans-cranial-stimulation (TMS), meditation-induced) are endogenously generated but they are experienced during wakefulness (except mediation-induced phosphenes: (Vimal \& Pandey-Vimal, 2007)) and hence they are close to SEs. Our PE-SE framework (Vimal, 2008) critically challenges existing theoretical perspectives that could significantly alter the directions of future research.

\subsubsection{Formation of neural-net and the emergence of SE: neural Darwinism}

In physicalism/neuroscience, we assume that SEs somehow emerge in neural-nets. The PE-SE framework (Vimal, 2008) hypothesizes that SEs arise out of the interaction of neural-PEs (PEs in the components of neural networks). In Vimal (2008, p. 59), the emergence of SEs was qualitatively unpacked as follows: "A hypothesis in the neural-based PE-SE framework is that (i) there exist a 'virtual reservoir' that stores all possible fundamental SEs/PEs, (ii) the interaction of stimulus dependent feed-forward and feedback signals in a neural-net creates a specific neural-net state, (iii) this specific state is assigned to a specific SE from the virtual reservoir during development and sensorimotor tuning by the evolutionary process of adaptation and natural selection (neural Darwinism), (iv) this specific SE is embedded as a memory trace of neural-net-PE," and (v) when a specific happiness-related stimulus (such as 'red rose') is presented to the amygdala-neural-net via visual neural-net, the associated specific SE, such as happiness, is selected by the matching and selection process and experienced by the amygdala-neuralnet. Let us call the steps (i)-(v) hypothesis $\mathbf{H}_{1}$. The generation of specificity involved in premises (iii)(v) can be further unpacked using neural Darwinism (Vimal, 2008). We argue that embedding process and matching-selection process for generating specificity of SE, in the PE-SE framework, can be addressed using the concept of co-development and sensorimotor co-tuning by the evolutionary process of adaptation and natural selection (neural Darwinism). As specific neural-net is formed via neural Darwinism, the specificity of the neural-net for SEs/PEs also increases. The emotion-related channels are calibrated during co-development and sensorimotor co-tuning (Vimal, 2008).

Furthermore, there are at least two complementary mechanisms for the selection of a specific SE (Vimal, 2008): (i) classical axonal-dendritic mechanism: in this mechanism, the specific SE is selected from the SEs embedded in neural-net based on the stimulus-dependent signals by matching process during the interaction of feed forward stimulus-dependent signals with fronto-parietal attentional feedback signals, and (ii) quantum dendritic-web mechanism: this is quantum Orch OR mechanism in MT network (Hameroff \& Penrose, 1998; Hameroff, 2007), where SE say happiness is selected from the SEs embedded in spacetime geometry by objective reduction (collapse) of superimposed SEs in the neuralnet to the specific SE say happiness when stimulus say 'red rose' is presented (assuming it is the happiness-related stimulus). Quantum conjugate matching (Globus, 1998, 2005) might also be involved. The coherence between feedforward incoming and reentrant feedback signals is necessary for SEs. Therefore, both mechanisms may involve matching process during interaction of feed forward stimulusdependent signals with fronto-parietal attentional feedback signals, where the SEs embedded in neuralnet/spacetime geometry match with the SE superimposed in external and/or internal stimulus-related signal for the selection of a specific SE.

According to (Vimal, 2008, p. 59), “The term 'virtual reservoir', in PE-SE framework, is consistent [with] our fundamental assumption that all types of fundamental SEs/PEs are in superimposed form ${ }^{4}$

\footnotetext{
${ }^{4}$ The term 'superimposition' refers to the process in which all kinds of SEs (over millions) are laid over on say electron. This means that an electron is not specific to any specific SE; and the electron acts as if it is a nonexperiential material entity. In PE-SE framework, an electron is a sort of proto-experiential (not proto-conscious) entity. This is because (a) electron cannot have SEs and (b) to have SE the entity/system needs to have essential ingredients of having SEs such as wakefulness, attention, re-entry, and memory (that is possible in neural-nets).
} 
in all elementary particles. Thus, every elementary particle can be considered as a virtual reservoir containing all types of fundamental SEs/PEs. Though apparently different, virtual reservoir can also be considered as a sort of 'Penrose Platonic world' in Orch OR framework (Hameroff \& Penrose, 1998)], 'societies of occasions of experience' or 'space for the qualia of material' in Whitehead framework (Whitehead, 1978; Baer, 2007)."

Alternatively, according to the principle of emergence, the physical property of salt $(\mathrm{NaCl})$ emerges from the interaction of its constituents $\mathrm{Na}^{+}$and $\mathrm{Cl}^{-}$ions. In analogy to this, a specific SE, such as happiness, can emerge in a relevant neural-net from interaction of its constituent neural-PEs in amygdala-neural-net: call it hypothesis $\mathbf{H}_{2}$. For example, the reportable SE happiness might have emerged during the interaction of two types of signals: (i) feedforward stimulus dependent PE-carrying-neuralsignal to amygdala system (call it FF) and (ii) feedback fronto-parietal attention related re-entrant PEcarrying-neural-signal (call it $\mathrm{FB})$, i.e., happiness $=(\mathrm{FF}) *(\mathrm{FB})$, in analogy to $\mathrm{NaCl}=\left(\mathrm{Na}^{+}\right)\left(\mathrm{Cl}^{-}\right)$. Another analogy is that water emerges from the interaction of hydrogen and oxygen; water is entirely new entity that is not in any way the sum of its parts. For non-reportable phenomenal SE, FB $=0$. Further research is needed to investigate if hypotheses $\mathrm{H}_{1}$ and $\mathrm{H}_{2}$ are complementary to each other or one of them needs to be rejected.

To sum up, there are two types of explanatory gaps: Type- 1 explanatory gap is how SEs can emerge from non-experiential matter. Type-2 explanatory gap is how it is possible that our SEs (such as happiness, sadness, painfulness, and similar SEs) were already present in primal entities, whereas there is no shred of evidence that such SEs were conceived at the onset of universe. To address these gaps, two working hypotheses are proposed: $\left(\mathbf{H}_{1}\right)$ String, elementary particles, and inert matter are the carriers of superimposed fundamental (not derived) ${ }^{5} \mathrm{SEs} / \mathrm{PEs}$, and neural Darwinism and matching-selection process help in generating and selecting a specific SE in a neural-net. $\left(\mathbf{H}_{2}\right)$ Fundamental entities and inert matter are the carriers of superimposed fundamental PEs (not SEs); there is a PE attached to every level of evolution (such as atomic-PE, molecular-PE, genetic-PE, neural-PE and so on); ${ }^{6}$ and a specific SE emerges in a neural-net from the interaction of its constituent neural-PEs, such as in feed forward stimulus-dependent neural signals and fronto-parietal feedback attentional signals, in analogy to water emerges from the interaction of hydrogen and oxygen. In both hypotheses, SEs emerge/arise when

\footnotetext{
${ }^{5}$ We used the concept of fundamental and derived SEs/PEs. SEs/PEs that can be derived from the irreducible fundamental SEs/PEs are called 'derived' or 'secondary' SEs/PEs. For example, happiness, sadness, and similar emotional SEs might have been derived from irreducible fundamental emotional-type proto-experience(s) interacting with the context of emotional stimuli. See also (Ekman, 1992; 1999) for basic emotions: "There are three meanings of the term "basic"... First, it distinguishes those who maintain that there are a number of separate emotions, that differ one from another in important ways. From this perspective, fear, anger, disgust, sadness and contempt, all negative emotions, differ in their appraisal, antecedent events, probable behavioral response, physiology and other characteristics described below. So, too, amusement, pride in achievement, satisfaction, relief and contentment, all positive emotions, differ from each other. This basic emotions perspective is in contrast to those who treat emotions as fundamentally the same, differing only in terms of intensity or pleasantness. [...] The second meaning of the adjective "basic" is to indicate instead the view that emotions evolved for their adaptive value in dealing with fundamental life tasks [such as achievements, losses, frustrations,]. Innate factors play a role in accounting for the characteristics they share, [...] in happiness a goal is attained or maintained, in sadness there is a failure to attain or maintain a goal, in anger an agent causes a loss of a goal, and in fear there is an expectation of failure to achieve a goal. [...] emotions are designed to deal with inter-organismic encounters, between people or between people and other animals. [...] [Third] The term "basic" has been used also to describe elements that combine to form more complex or compound emotions. So, for example, smugness might be considered to be a blend of the two elemental emotions, happiness and contempt." (Ekman, 1999, first and second pages of Chapter 3).
}

${ }^{6}$ In hypothesis $\mathrm{H}_{2}$, since PE co-evolves with matter, $\mathrm{PE}$ (the mental aspect of an entity) is inter-dependent on the structure and function of material aspect of that entity. For example, the water-PE (liquidity/liquidness) is interdependent on structure and function of the liquid water, ice-PE (solidity/solidness) on that of ice, steam-PE on that of steam. Similarly, the SE happiness is inter-dependent on the structure and function of happiness-related amygdala neural-net and emerges during the interaction of two types of signals (feed forward and feedback neural signals). 
essential ingredients of SEs (such as wakefulness, attention, re-entry, working memory and so on) are satisfied. Perhaps, hypothesis $\mathrm{H}_{2}$ appears to be more interesting to neuroscientists because of the Type2 explanatory gap implicit in hypothesis $\mathrm{H}_{1}$.

\section{Future Directions}

There are brain areas that are 'common' to five forms of attention tasks and there are areas 'specific' to a specific form of attention task. The common areas might be ACC and middle frontal gyrus (MFG) (Posner \& Petersen, 1990; Corbetta et al. 1991; Vandenberghe et al., 1997; Coull, 1998; Kastner et al., 1999; DiGirolamo et al., 2001; Sarter et al., 2001; Luks et al., 2002; Rushworth et al., 2002; Barrett et al., 2003; Booth et al., 2003; Swainson et al., 2003; Sylvester et al., 2003; Wylie et al., 2003; Peelen et al., 2004). The neural correlate of top-down and bottom-up attention ('sources' of attentional signal) involves those areas that are significantly activated by attentional modulations. Such sources may include frontal cortex (such as ACC, MFG, DLPFC, VLPFC) (Buchel \& Friston, 1997; Rowe et al., 2002a,b), and thalamic reticular nucleus (TRN) (Scheibel \& Scheibel, 1966; Yingling \& Skinner, 1977; Crick, 1984; Mitrofanis \& Guillery, 1993; Baars, 1995; Kinsbourne, 1995). However, there is no consensus because the experiments for all five forms of attention are not yet performed to isolate attentional areas systematically from 'other' activated areas for the same subjects in the same laboratory using the same stimulus conditions. For this purpose, a group of experiments can investigate further and test if ACC and MFG are the only 'common' areas and the frontal cortex and TRN are the only areas for the 'sources' of attentional signal with normal subjects. The test stimuli can be related to face recognition, emotion, reward, working memory or awareness with high and low level of attention for luminance or Red-Green color channel (Vimal, 1997, 1998a,b, 2000, 2002a,b). The 'targets' of attentional signal depend on the test stimulus. For example, the 'targets' of attention may include GF for face recognition, amygdala for emotion, 'NAc, amygdala, SLEA of the basal forebrain, hypothalamus, $\mathrm{GOb}$, and VT of the midbrain in humans' for reward, and PFC for working memory related stimuli. However, it would be initially more efficient to focus on selective attention to investigate its effects on face recognition and facial emotion (Baudouin et al., 2002; Pessoa et al., 2002; Geday et al., 2003; Small et al., 2003; Shin et al., 2005).

A simple fMRI experimental protocol to separate attentional areas from 'other' areas can have just 3 conditions: (i) 'looking at white fixation light on dark background (F)', (ii) 'fixation at the center without attention to the test stimulus (N)', and (iii) 'fixation at the center and high level of attention to the test stimulus (A)'. Psychophysical studies such as ours on visual mechanisms (Vimal, 1997, 1998a, b, 2000, 2002a, b) were performed with high degree of attention. The activated areas involved in attention tasks can be grouped as follows:

$$
\begin{aligned}
& F=A_{f}+O_{f} \\
& N=A_{f}+O_{f}+A_{n}+O_{n} \\
& A=A_{f}+O_{f}+A_{h}+O_{h}
\end{aligned}
$$

In the right side of above equations, ' $\mathrm{A}$ ' and ' $\mathrm{O}$ ' indicate attentional and 'other' areas, respectively. Subscripts ' $\mathrm{f}$ ', ' $\mathrm{n}$ ', and ' $\mathrm{h}$ ' represent foveal, no-attention, and high-attention conditions, respectively. We assume that the activation $A_{n}$ is small, $O_{n} \sim O_{h}$ and $A_{h}>A_{n}$. The subtraction maps $(A-N) \sim\left(A_{h}-\right.$ $\left.\mathrm{A}_{\mathrm{n}}\right) \sim \mathrm{A}_{\mathrm{h}}$ can separate attentional areas and $\left[(\mathrm{A}-\mathrm{F})-\mathrm{A}_{\mathrm{h}}\right] \sim \mathrm{O}_{\mathrm{h}}$ can separate 'other' areas. 'Other' areas include all the remaining areas other than attentional areas that may be activated in visual attention tasks, and can be grouped as follows: (i) visual areas (such as V1 and V2) for both color and luminance contrasts, (ii) visual areas (such as 'V8/V4/VO') for 'only color contrast' and color identification, (iii) motion areas (such as V5), (iv) areas involved in specifying the location of stimulus (such as parietal areas), (v) areas involved in the stimulus-identification (such as IT), (vi) preparatory eye movement areas (such as FEF), (vii) areas involved in face recognition (such as GF), (viii) areas involved in emotions (such as amygdala), (ix) areas involved in reward system (such as NAc, amygdala, SLEA of the basal forebrain, hypothalamus, GOb, and VT of the midbrain in humans), (x) areas involved in 
working memory (such as PFC), and (xi) areas for iconic memory, long term memory, task performance, thought processing, perceptual categorization, reasoning, planning, evaluation of alternatives, decisionmaking, rational control of action, and so on. The definition of 'other' areas is variable; for example, if more conditions are included in fMRI sessions to isolate areas mentioned in (i)-(x) then the definition of 'other' area will be limited to the areas specified in (xi).

In the proposed fMRI experiment, A condition (with attention) and $\mathrm{N}$ condition (without attention) are distinguished from each other by different instructions. Therefore, when test stimuli were chosen from emotionally salient stimuli such as facial expressions and rewarding stimuli, $\mathrm{N}$ condition would probably recruit extra neural components related to suppressing automatic attentional (or gaze) shift towards emotional stimuli. This should be appropriately considered in analysis.

The idea behind separating top-down and bottom-up forms of attentional modulation is interesting. For example, in selective attention, TRN is involved in bottom-up and fronto-parietal areas are involved in top-down attentional modulation. In rapid vision $(<120 \mathrm{~ms})$ and pop-out search, topdown attentional modulation may not be involved (Koch \& Tsuchiya, 2007). Therefore, our prediction is that an appropriate selection of stimuli for fMRI study will separate bottom-up and top-down attentional modulation and perception.

\section{Concluding Remarks}

This article is a review of neuroscience research on attention and emotion. The review involves various definitions of attention and different sorts of tasks to measure it with an emphasis on visual attention, and a discussion of emotion with an emphasis on face recognition, facial emotion, and reward systems. Subsequent there is a discussion on the interactions between attention and emotion, which differentiates reward conditioning and face recognition from the global concept of emotional processing. The influence of emotion on attention switching is also mentioned. At the end, an fMRI experiment is also suggested in order to make it easier to determine the influence of selective attention on emotion and to resolve controversies in attention research.

A simple working hypothesis is as follows: Attention is a neural signal (can be reentrant signal such as FEF $\leftrightarrow$ V4) that modulates the stimulus related feed forward signal. Emotion is feeling related affective subjective experience or first person experience, such as happiness, sadness, and so on. Its neural correlate is amygdala-neural-net. The attentional modulating signal could be in forward (bottomup) direction or mostly in backward (top-down) direction. The attention could be at foveal or peripheral targets for long (sustained) or short (transient) duration. The 'sources' of attention may be TRN for bottom-up or frontal cortex (such as ACC, MFG) for top-down direction. The 'targets' of attention may be GF for face recognition, amygdala for emotion, and 'NAc, amygdala, SLEA of the basal forebrain, hypothalamus, GOb, and VT of the midbrain in humans' for reward system.

The areas for the 'sources' of attention (where attentional signal is generated) and 'targets' of attention (where attentional signal modulates the main signal) need to be carefully separated to make the attention research simple and to resolve controversies (see Section 4).

Furthermore, to link the structure and function related to emotion with its subjective experiences, we extended the dual-aspect PE-SE framework (Vimal, 2008) to emotion, which addressed the explanatory gaps related to emotional subjective experiences.

\section{Acknowledgments}

Author would like to thank anonymous reviewers, Vivekanand Pandey Vimal, Shalini Pandey Vimal, Love (Shyam) Pandey Vimal, and Manju-Uma C. Pandey-Vimal for their critical comments, suggestions, and grammatical corrections; and Christof Koch, Alfredo Pereira Jr., and Ronald J. MacGregor for useful information in email correspondence.

\section{Competing Interests Statement}

The author declares that he has no competing financial interests. 


\section{References}

Adolphs R, Damasio H, Tranel D, Damasio AR. Cortical systems for the recognition of emotion in facial expressions. J Neurosci 1996;16(23):7678-87.

Adolphs R, Tranel D, Buchanan TW. Amygdala damage impairs emotional memory for gist but not details of complex stimuli. Nat Neurosci 2005;8:512-8.

Aggleton JP, Burton MJ, Passingham RE. Cortical and subcortical afferents to the amygdala in the rhesus monkey (Macaca mulatta). Brain Res 1980;190:347-68.

Aharon I, Etcoff N, Ariely D, Chabris CF, O'Connor E, Breiter HC. Beautiful Faces Have Variable Reward Value: fMRI and Behavioral Evidence. Neuron 2001;32:537-51.

Amaral DG, Price JL, Pitkanen A, Carmichael ST. Anatomical organization of the primate amygdala complex. In: Aggleton JP (editor). The Amygdala. New York: John Wiley-Liss, 1992.

Andreasen NC, O'Leary DS, Arndt S, et al. Neural substrates of facial recognition. J Neuropsych 1996;8:139-46.

Baars B. Tutorial commentary: surprisingly small subcortical structures are needed for the state of waking consciousness, while cortical projection areas seem to provide perceptual contents of consciousness. Conscious Cogn 1995;4(2):159-62; Comment on: Conscious Cogn 1995;4(2):137-58.

Baer W. The Physical Condition for Consciousness: A comment on R. Shaw and J. Kinsella-Shaw. J Consciousness Stud 2007;14(8):93-104.

Barrett NA, Large MM, Smith GL, et al. Human brain regions required for the dividing and switching of attention between two features of a single object. Cognit Brain Res 2003;17:1-13.

Bartels A, Zeki S. The architecture of the colour centre in the human visual brain: new results and a review. Eur J Neurosci 2000;12:172-93.

Baudouin JY, Martin F, Tiberghien G, Verlut I, Franck N. Selective attention to facial emotion and identity in schizophrenia. Neuropsychologia 2002;40(5):503-11.

Berridge KC. Food reward: brain substrates of wanting and liking. Neurosci Behav Rev 1996;20:1-25.

Berridge KC. Reward learning: reinforcement, incentives and expectations. In: Medin DL, ed. The Psychology of Learning and Motivation. New York: Academic Press; 2000.

Berridge KC, Robinson TE. Parsing reward. Trends Neurosci 2003; 26:507-13.

Booth JR, Burman DD, Meyer JR, et al. Neural development of selective attention and response inhibition. NeuroImage 2003; 20:737-51.

Breiter HC, Aharon I, Kahneman D, Dale A, Shizgal P. Functional Imaging of Neural Responses to Expectancy and Experience of Monetary Gains and Losses. Neuron 2001;30:619-39.

Breiter HC, Etcoff NL, Whalen PJ, et al. Response and habituation of the human amygdala during visual processing of facial expression. Neuron 1996;17(5):875-87.

Breiter HC, Rosen BR. Functional Magnetic Resonance Imaging of Brain Reward Circuitry in the Human. Ann N Y Acad Sci 1999;877:523-47.

Britton JC, Shin LM, Barrett LF, Rauch SL, Wright CI. Amygdala and fusiform gyrus temporal dynamics: responses to negative facial expressions. BMC Neurosci 2008;9:44.

Broks P, Young AW, Maratos EJ, et al. Face processing impairments after encephalitis: amygdala damage and recognition of fear. Neuropsychologia 1998;36(1):59-70.

Bruce V. Changing faces: visual and nonvisual coding processes in face recognition. Brit J Psychol 1982;16:73-105.

Bruce V. Influences of familiarity on the processing of faces. Perception 1986;15:387-97.

Bruce V, Young AW. Understanding face recognition. Brit J Psychol 1986;77:305-27.

Bruzzo AA, Vimal RLP. Self: An adaptive pressure arising from self-organization, chaotic dynamics, and neural Darwinism. J Integr Neurosci 2007;6(4):541-66.

Buchel C, Friston KJ. Modulation of connectivity in visual pathways by attention: cortical interactions evaluated with structural equation modelling and fMRI. Cereb Cortex 1997;7(8):768-78.

Bushnell PJ, Levin ED, Marrocco RT, Sarter MF, Strupp BJ, Warburton DM. Attention as a target of intoxication: insights and methods from studies of drug abuse. Neurotoxicol Teratol 2000;22(4):487-502.

Cador M, Robbins TW, Everitt BJ. Involvment of the amygdala in stimulus-reward association: interaction with the ventral stratium. Neuroscience 1989;30(1):77-86. 
Cahill L, McGaugh JL. Mechanisms of emotional arousal and lasting declarative memory. Trends Neurosci 1998;21(7):294-9.

Campbell R, Brooks B, De Haan E, Roberts T. Dissociating face processing skills: Decisions about lipread speech, expression, and identity. Q J Exp Psychol 1996;49A:295-314.

Carvajal F, Rubio S, Martin P, Amarante C, Garcia-Sola R. The role of the amygdala in facial emotional expression during a discrimination task. Psicothema 2007;19(1):23-9.

Chalmers DJ. Facing up to the problem of consciousness. Journal of Consciousness Studies 1995; 2: 200-19.

Cheal M, Lyon DR. Central and peripheral precuing of forced-choice discrimination. Q J Exp Psychol A 1991;43(4):859-80.

Corbetta M, Shulman GL. Control of goal-directed and stimulus-driven attention in the brain. Nat Rev Neurosci 2002;3(3):201-15.

Corbetta M, Miezin FM, Dobmeyer S, Shulman GL, Petersen SE. Selective and divided attention during visual discriminations of shape, colour, and speed: functional anatomy by Positron Emission Tomography. J Neurosci 1991;11:2383-402.

Coull JT. Neural correlates of attention and arousal: insights from electrophysiology, functional neuroimaging and psychopharmacology. Prog Neurobiol 1998;55(4):343-61.

Crick F. Function of the thalamic reticular complex: the searchlight hypothesis. Proc Natl Acad Sci U S A 1984;81:4586-90.

Cunningham M, Roberts AR, Barbee AP, Cruen PB, Wu C-H. Consistency and variability in the crosscultural perception of female physical attractiveness. J Pers Soc Psychol 1995;68:261-79.

Damasio AR. The Feeling of What Happens: Body and Emotion in the Making of Consciousness. New York: Harcourt Brace, 1999.

Damasio AR, Grabowski TJ, Bechara A, et al. Subcortical and cortical brain activity during the feeling of self-generated emotions. Nat Neurosci 2000;3(10):1049-56.

Davidson RJ, Irwin W. The functional neuroanatomy of emotion and affective style. Trends Cognit Sci 1999;3(1):11-21.

Desimone DR, Duncan J. Neural mechanisms of selective attention. Annu Rev Neurosci 1995; 18:193-222.

Delgado MR, Nystrom LE, Fissell K, Noll DC, Fiez JA. Tracking the hemodynamic responses for reward and punishment in the striatum. J Neurophys 2000;84:3072-7.

DiGirolamo GJ, Kramer AF, Barad V, et al. General and task-specific frontal lobe recruitment in older adults during executive processes: a fMRI investigation of task-switching. Neuroreport 2001;12(9):2065-71.

Edelman GM. Naturalizing consciousness: a theoretical framework. Proc Natl Acad Sci USA 2003;100(9):5520-4.

Eerikäinen A. Time and Polarity: The Dimensional Thinking of Karl Heim. Helsinki: Yliopistopaino: University of Helsinki; 2000.

Ekman P. Are there basic emotions? Psychol Rev 1992;99(3):550-3.

Ekman P. Facial expression and emotion. Am Psychol 1993;48(4):384-92.

Ekman P. Basic Emotions (Chapter 3). In: Dalgleish T, Power M (editors). Handbook of Cognition and Emotion. Sussex, UK: John Wiley \& Sons, Ltd, 1999.

Ekman P. Darwin, deception, and facial expression. Ann N Y Acad Sci 2003;1000:205-21.

Elliott R, Friston KJ, Dolan RJ. Dissociable neural responses in human reward systems. J Neurosci 2000;20:6159-65.

Engel GS, Calhoun TR, Read EL, et al. Evidence for wavelike energy transfer through quantum coherence in photosynthetic systems. Nature 2007;446(7137):782-6.

Everitt BJ, Morris KA, O'brien A, Robbins TW. The basolateral amygdala-ventral striatal system and conditioned place preference: further evidence of limbic-striatal interactions underlying rewardrelated processes. J Neurosci 1991;42:1-18.

Fell J. Identifying neural correlates of consciousness: The state space approach. Conscious Cognit 2004;13:709-29. 
Festman Y, Ahissar M. Attentional effects on adaptation to gratings. In: 26th European Conference on Visual Perception. Perception: ECVP 2003 abstracts. Universite Rene Descartes, Paris, France; 2003.

Filipek P, Richelme C, Kennedy D, Caviness V. The young adult human brain: an MRI-based morphometric analysis. Cerebr Cortex 1994;4:344-60.

Fuster JM. The Prefrontal Cortex: Anatomy, Physiology, and Neuropsychology of the Frontal Lobe. Philadelphia: Lippincott-Raven, 1997.

Gaffan D, Harrison. S. Disconnection of the amygdala from visual association cortex impairs visual reward-association learning in monkeys. J Neurosci 1988; 8:3144-50.

Gallagher M, Chiba AA. The amygdala and emotion. Curr Opin Neurobiol 1996;6:221-7.

Gallagher S. Neurocognitive models of schizophrenia: a neurophenomenological critique. Psychopathology 2004;37(1):8-19. Epub 2004 Feb 24. Comment in: Psychopathology 2004;37(1):20-2.

Gallagher M, Holland PC. The amygdala complex: multiple roles in associative learning and attention. Proc Natl Acad Sci USA 1994;91:11771-6.

Geday J, Gjedde A, Boldsen AS, Kupers R. Emotional valence modulates activity in the posterior fusiform gyrus and inferior medial prefrontal cortex in social perception. Neuroimage 2003;18(3):675-84.

George MS, Ketter TA, Gill DS, et al. Brain regions involved in recognizing facial emotion or identity: an oxygen-15 PET study. J Neuropsych 1993;5:384-94.

Globus GG. Self, Cognition, Qualia and World in Quantum Brain Dynamics. Journal of Consciousness Studies 1998;5(1):34-52.

Globus GG. The being/brain problem. NeuroQuantology 2005;4:256-63.

Gray JA. A model of the limbic system and basal ganglia: Application to anxiety and schizophrenia. In: Gazzaniga MS, ed. The cognitive neurosciences. Cambridge, MA: MIT Press; 1995:1165-76.

Gur RE, McGrath C, Chan RM, et al. An fMRI Study of Facial Emotion Processing in Patients with Schizophrenia. Am J Psychiatr, 2002;159:1992-9.

Hadjikhani N, Liu AK, Dale AM, Cavanagh P, Tootell RB. Retinotopy and color sensitivity in human visual cortical area V8. Nat Neurosci 1998;1(3):235-24; Comment in: Nat Neurosci 1998 Jul;1(3):171-3. Comment in: Nat Neurosci Sep;1(5):335-6.

Hamker FH. The Reentry Hypothesis: The Putative Interaction of the Frontal Eye Field, Ventrolateral Prefrontal Cortex, and Areas V4, IT for Attention and Eye Movement. Cerebr Cortex 2004;15(4):431-47.

Hameroff S, Penrose R. Quantum computation in brain microtubules? The Penrose-Hameroff 'Orch OR' model of consciousness. Philos Trans R Soc London 1998;Ser. A 356:1869-96.

Hameroff S. Schrödinger's proteins: how quantum biology can explain consciousness. In: Berrnroider G, Hameroff S (editors). Quantum Mind 2007. The University of Salzburg, Salzburg, Austria. Consciousness Research Abstracts: a service from the Journal of consciousness Studies; pages 1112 (abstract number 7); 2007.

Hasselmo ME, Rolls ET, Baylis GC. The role of expression and identity in the face-selective responses of neurons in the temporal visual cortex of the monkey. Behav Brain Res 1989;32:203-18.

Hatfield T, Han J-S, Conley M, Gallagher M, Holland P. Neurotoxic lesions of basolateral, but not central, amygdala interfere with pavlovian second-order conditioning and reinforcer devaluation effects. J Neurosci 1996;16:5256-65.

Hawkins HL, Hillyard SA, Luck SJ, Mouloua M, Downing C, Woodward DP. Visual attention modulates signal detectability. J Exp Psychol Hum Percept Perform 1990;16:802-11.

Haxby JV, Hoffman EA, Gobbini MI. Human neural systems for face recognition and social communication. Biol Psychiatr Res 2002; 51:59- 67.

Holland PC, Gallagher M. Amygdala circuitry in attentional and representational processes. Trends Cognit Sci 1999;3(2):65-73.

Huang L, Dobkins KR. Attentional effects on contrast discrimination in humans: evidence for both contrast gain and response gain. Vision Res 2005;45(9):1201-12.

James W. The Principles of Psychology. New York: Henry Holt, 1890.

Jones DM, Hill K. Criteria of facial attractiveness in five populations. Hum Nat 1993;4:271-96. 
Kanwisher N, Wojciulik E. Visual attention: insights from brain imaging. Nat Rev Neurosci 2000;1(2):91-100.

Kanwisher N, McDermott J, Chun MM. The fusiform face area: a module in human extrastriate cortex specialized for face perception. J Neurosci 1997;17(11):4302-11.

Kant I. Observations on the Feeling of the Beautiful and Sublime (Trans Goldthwait, J.T.U. California Press, original 1763-64). 1960.

Kastner S, Pinsk MA, De Weerd P, Desimone R, Ungerleider LG. Increased activity in human visual cortex during directed attention in the absence of visual stimulation. Neuron 1999;22:751-61.

Keil A, Moratti S, Sabatinelli D, Bradley MM, Lang PJ. Additive effects of emotional content and spatial selective attention on electrocortical facilitation. Cerebr Cortex 2005;15(8):1187-97.

Kinsbourne M. The Intralaminar Thalmic Nuclei: Subjectivity Pumps or Attention-Action Coordinators? Conscious Cognit 1995;4(2):167-71.

Koch C, Tsuchiya N. Attention and Consciousness: Two Distinct Brain Processes. Trends Cognit Sci 2007;11:16-22.

Knutson B, Westdorp A, Kaiser E, Hommer D. FMRI visualization of brain activity during a monetary incentive delay task. NeuroImage, 2000;12:20-7.

Kranczioch C, Debener S, Schwarzbach J, Goebel R, Engela AK. Neural correlates of conscious perception in the attentional blink. NeuroImage 2005;24:704-14.

Kustov AA, Robinson DL. Shared neural control of attentional shifts and eye movements. Nature 1996;384(6604):74-7.

Lamme VA. Why visual attention and awareness are different. Trends Cognit Sci 2003;7(1):12-8.

Langlois JH, Ritter JM, Riggman LA, Vaughn LS. Facial diversity and infant preferences for attractive faces. Dev Psychol 1991;27:79-84.

Lazarus R. Emotion and Adaptation. New York: Oxford University Press, 1991.

LeDoux JE. The Emotional Brain. New York: Simon and Schuster; 1996.

LeDoux JE. In search of an emotional system in the brain: leaping from fear to emotion and consciousness. In: Gazzaniga MS (editor). The Cognitive Neurosciences. Cambridge, MA: MIT Press, 1995.

LeDoux JE. Emotion and the amygdala. In: Aggleton JP, ed. The amygdala: neurobiological aspects of emotion, memory and mental dysfunction. New York: Wiley-Liss; 1992:339-51.

Lehky SR. Temporal properties of visual channels measured by masking. J Opt Soc Am [A] 1985;2:1260-72.

Leonard CM, Rolls ET, Wilson FA, Baylis GC. Neurons in the amygdala of the monkey with responses selective for faces. Behav Brain Res 1985;15:159-76.

Levine J. Materialism and qualia: The explanatory gap. Pacific Philosophical Quarterly 1983;64:354-61.

Levinoff EJ, Li KZ, Murtha S, Chertkow H. Selective attention impairments in Alzheimer's disease: evidence for dissociable components. Neuropsychol 2004;18(3):580-8.

Ling S, Carrasco M. Sustained and transient covert attention enhance the signal via different contrast response functions. Vis Res 2006;46(8-9):1210-20.

Luks TL, Simpson GV, Feiwell RJ, Miller WL. Evidence for anterior cingulate cortex involvement in monitoring preparatory attentional set. NeuroImage 2002;17(2):792-802.

MacGregor RJ, Vimal RLP. Consciousness and the Structure of Matter. J Integr Neurosci 2008;7(1):75-116.

Mitrofanis J, Guillery RW. New views of the thalamic reticular nucleus in the adult and the developing brain. Trends Neurosci 1993;16:240-5.

Moratti S, Keil A, Stolarova M. Motivated attention in emotional picture processing is reflected by activity modulation in cortical attention networks. NeuroImage 2004;21(3):954-64.

Monk CS, Klein RG, Telzer EH, et al. Amygdala and nucleus accumbens activation to emotional facial expressions in children and adolescents at risk for major depression. Am J Psychiatr 2008;165(1):90-8.

Nachson I. On the modularity of face recognition: the riddle of domain specificity. J Clin Exp Neuropsychol 1995;17:256-75.

Nakayama K, Mackeben M. Sustained and transient components of focal visual attention. Vision Res 1989;29(11):1631-47. 
Parasuraman R. The psychobiology of sustained attention. In: Warm JS (editor). Sustained Attention in Human Performance. Chichester: John Wiley, 1984.

Peelen MV, Heslenfeld DJ, Theeuwes J. Endogenous and exogenous attention shifts are mediated by the same large-scale neural network. NeuroImage 2004;22(2):822-30.

Pereira Jr. A. Astrocyte-Trapped Calcium Ions: the Hypothesis of a Quantum-Like Conscious Protectorate. Quantum Biosystems 2007a;2:80-92.

Pereira Jr. A. The Encapsulated Protectorate: a Non-Reductive Physicalist Approach to Consciousness. In: Towards a Science of Consciousness, Budapest Abstract Book published by the Hungarian Cognitive Science Foundation, p 77; http://wwwtsc2007org/ TSC2007abstractspdf; 2007b; 2007. p. 77.

Pereira Jr. A, Furlan FA. Biomolecular Information, Brain Activity and Cognitive Functions. Annu Rev Biomed Sci 2007a;9:12-29.

Pereira Jr. A, Furlan FA. Meta-Potentiation: Neuro-Astroglial Interactions Supporting Perceptual Consciousness. Nature Proceedings: http://precedingsnaturecom/documents/760/version/1 2007b:1-15.

Perrett DI, Heitanen JK, Oram MW, Benson PJ. Organization and functions of cells responsive to faces in the temporal cortex. Phil Trans Roy Soc Lond B Biol Sci 1992;335:31-8.

Perrett DI, May KA, Yoshikawa S. Facial shape and judgments of female attractiveness. Nature 1994;368:239-42.

Perrett DI, Rolls ET, Caan W. Visual neurons responsive to faces in the monkey temporal cortex. Exp Brain Res 1982;47:329-42.

Pessoa L, Kastner S, Ungerleider LG. Attentional control of the processing of neutral and emotional stimuli. Cognit Brain Res 2002;15:31-45.

Pitkanen A. Connectivity of the rat amygdaloid complex. In: Aggleton JP (editor). The Amygdala: A Functional Analysis. Oxford, UK: Oxford University Press, 2000.

Pinault D. The thalamic reticular nucleus: structure, function and concept. Brain Res Rev 2004;46(1):1-31.

Posner MI, Petersen SE. The attention system of the human brain. Annu Rev Neurosci 1990;13:25-42.

Puce A, Allison T, Asgari M, Gore JC, McCarthy G. Differential sensitivity of human visual cortex to faces, letterstrings, and textures: a functional magnetic resonance imaging study. J Neurosci 1996;16:5205-15.

Reddy L, Wilken P, Koch C. Face-gender discrimination is possible in the near-absence of attention. J Vis 2004;4(2):106-17.

Robinson TE, Berridge KC. The neural basis of drug craving: an incentive-sensitization theory of addiction. Brain Res Rev 1993;18:247-91.

Rogers RD, Monsell S. Costs of a predictable switch between simple cognitive tasks. J Exp Psychol Gen 1995;124(2):207-31.

Rolls ET. Neurons in the cortex of the temporal lobe and in the amygdala of the monkey with responses selective for faces. Hum Neurobiol 1984;3:209-22.

Rolls ET. Connections, functions and dysfunctions of limbic structures, the prefrontal cortex, and hypothalamus. In: Swash M, Kennard C (editors). The Scientific Basis of Clinical Neurology. London: Churchill Livingstone, 1985.

Rolls ET. The processing of face information in the primate temporal lobe. In: Bruce V, Burton M, eds. Processing Images of Faces. Norwood, NJ: Ablex.; 1991.

Rolls ET. A theory of emotion and consciousness, and its application to understanding the neural basis of emotion. In: Gazzaniga MS (editor). The Cognitive Neurosciences. Cambridge, MA: MIT Press, 1995.

Rolls ET. The Brain and Emotion. Oxford: University of Oxford Press; 1999.

Rolls ET, Treves A. Neural Networks and Brain Function. Oxford, UK.: Oxford University Press; 1998.

Roozendaal B, Sapolsky RM, McGaugh JL. Basolateral amygdala lesions block the disruptive effects of long-term adrenalectomy on spatial memory. Neuroscience 1998;84(2):453-65. 
Rowe J, Stephan KE, Friston K, Frackowiak R, Lees A, Passingham R. Attention to action in Parkinson's disease: impaired effective connectivity among frontal cortical regions. Brain 2002a;125(Pt 2):276-89.

Rowe J, Friston K, Frackowiak R, Passingham R. Attention to action: specific modulation of corticocortical interactions in humans. NeuroImage 2002b;17(2):988-98.

Rosenzweig MR, Leiman AL. Physiological psychology. Lexington, MA: D. C. Heath and Company; 1982.

Rushworth MF, Hadland KA, Paus T, Sipila PK. Role of the human medial frontal cortex in task switching: a combined fMRI and TMS study. J Neurophysiol 2002;87(5):2577-92.

Russchen FT, Bakst I, Amaral DG, Price JL. The amygdalostiatal projections in the monkey. An anterograde tracing study. Brain Res 1985; 329:241-57.

Sander D, Grandjean D, Pourtois G, et al. Emotion and attention interactions in social cognition: brain regions involved in processing anger prosody. NeuroImage 2005;28(4):848-58.

Sansone S, Tiberghien G. Traitement de l'expression faciale et reconnaissance des visages: indépendance ou interdépendance? [facial expression processing and face recognition: indépendence or interdépendence?]. Psychologie Française 1994;39:327-44.

Sarter M, Givens B, Bruno JP. The cognitive neuroscience of sustained attention: where top-down meets bottom-up. Brain Res Rev 2001;35:146-60.

Scheibel ME, Scheibel AB. The organization of the nucleus reticularis thalami: a Golgi study. Brain Res 1966;1:43-62.

Scherer K. What are emotions and how can they be measured? Soc Sci Inform 2005;44(4):695-729.

Schweinberger SR, Burton AM, Kelly SW. Asymmetric relationship between identity and emotion perception: experiments with morphed faces. Percept Psychophys 1999;61:1102-15.

Schweinberger SR, Soukup GR. Asymmetric relationships among perceptions of facial identity, emotion, and facial speech. J Exp Psychol Hum Percept Perform 1998;24:1748-65.

Sergent J, Ohta S, MacDonald B, Zuck E. Segregated processing of facial identity and emotion in the human brain: a PET-scan study. In: Bruce V, Humphreys GW (editors). Object and Face Recognition. Hillsdale, NJ: Lawrence Erlbaum, 1994.

Shin LM, Wright CI, Cannistraro PA, et al. A functional magnetic resonance imaging study of amygdala and medial prefrontal cortex responses to overtly presented fearful faces in posttraumatic stress disorder. Arch Gen Psychiatry 2005;62(3):273-81.

Slater A, Von der Schulenburg C, Brown E, et al. Newborn infants prefer attractive faces. Infant Behav Dev 1998;21:345-54.

Slotnick SD, Schwarzbach J, Yantis S. Attentional inhibition of visual processing in human striate and extrastriate cortex. NeuroImage 2003;19(4):1602-11.

Small DM, Gitelman DR, Gregory MD, Nobre AC, Parrish TB, Mesulam MM. The posterior cingulate and medial prefrontal cortex mediate the anticipatory allocation of spatial attention. NeuroImage 2003;18(3):633-41.

Smith GL, Large MM, Kavanagh DJ, et al. Further evidence for a deficit in switching attention in schizophrenia. J Abnorm Psychol 1998;107:390-8.

Somers DC, Dale AM, Seiffert AE, Tootell RB. Functional MRI reveals spatially specific attentional modulation in human primary visual cortex. Proceedings of the National Academy of Science 1999;96:1663-8.

Spiegler BJ, Mishkin M. Evidence for the sequential participation of inferior temporal cortex and amygdala in the acquisition of stimulus-reward associations. Behav Brain Res 1981;3:303-17.

Stormark KM, Hugdahl K. Peripheral cuing of covert spatial attention before and after emotional conditioning of the cue. Int J Neurosci 1996;86(3-4):225-40.

Swainson R, Cunnington R, Jackson GM, et al. Cognitive control mechanisms revealed by ERP and fMRI: evidence from repeated task-switching. J Cognit Neurosci 2003;15(6):785-99.

Sylvester CY, Wager TD, Lacey SC, et al. Switching attention and resolving interference: fMRI measures of executive functions. Neuropsychologia 2003;41(3):357-70. 
Tabert MH, Borod JC, Tang CY, et al. Differential amygdala activation during emotional decision and recognition memory tasks using unpleasant words: an fMRI study. Neuropsychologia 2001;39(6):556-73.

Tootell RB, Reppas JB, Kwong KK, et al. Functional analysis of human MT and related visual cortical areas using magnetic resonance imaging. J Neurosci, 1995;15(4):3215-30.

Tootell RBH, Tsao D, Vanduffel W. Neuroimaging Weighs In: Humans Meet Macaques in "Primate" Visual Cortex. Journal Neurosci 2003;23(10):3981-9.

Treue S. Neural correlates of attention in primate visual cortex. Trends Neurosci 2001;24(5):295-300.

Treue S. Visual attention: the where, what, how and why of saliency. Curr Opin Neurobiol 2003;13(4):428-32.

Vandenberghe R, Duncan J, Dupont P, et al. Attention to one or two features in left or right visual field: a positron emission tomography study. J Neurosci 1997;17(10):3739-50.

Vandenberghe R, Dupont P, De Bruyn B, et al. The influence of stimulus location on the brain activation pattern in detection and orientation discrimination: a PET study of visual attention. Brain 1996;119:1263-76.

Vasterling JJ, Duke LM, Brailey K, Constans JI, Allain AN, Jr., Sutker PB. Attention, learning, and memory performances and intellectual resources in Vietnam veterans: PTSD and no disorder comparisons. Neuropsychology 2002;16(1):5-14.

Vimal RLP. Orientation tuning of the spatial-frequency-tuned mechanisms of the Red-Green channel. J Opt Soc Am A 1997;14:12622-2632; Errata, J Opt Soc Am A 15, 758.

Vimal RLP. Color-luminance interaction: data produced by oblique cross masking. J Opt Soc Am A 1998a;15:1756-66; Errata, J Opt Soc Am A 15, 2931.

Vimal RLP. Spatial-frequency tuning of sustained nonoriented units of the Red-Green channel. J Opt Soc Am A 1998b;15:1-15.

Vimal RLP. Spatial color contrast matching: broad-bandpass functions and the flattening effect. Vis Res 2000;40(23):3231-43.

Vimal RLP. Spatial frequency tuned mechanisms of the Red-Green channel estimated by oblique masking. J Opt Soc Am A 2002a;19(2):276-88.

Vimal RLP. Spatial frequency discrimination: a comparison of achromatic and chromatic conditions. Vis Res 2002b;42(5):599-611.

Vimal RLP. Proto-experiences and Subjective Experiences. In: Berrnroider G, Hameroff S, editors. Quantum Mind 2007; 2007 July 16-20; The University of Salzburg, Salzburg, Austria. Consciousness Research Abstracts: a service from the Journal of consciousness Studies; pages 110-111 (abstract number 111).

Vimal RLP. Proto-experiences and Subjective Experiences: Classical and Quantum Concepts. J Integrat Neurosci 2008;7(1):49-73.

Vimal RLP, Davia CJ. How Long is a Piece of Time? - Phenomenal Time and Quantum Coherence Toward a Solution. Quantum Biosystems 2008;2:102-51. Available at http://www.quantumbionet.org/ admin/files/QBS2\%20102-151.pdf.

Vimal RLP, Pandey-Vimal M-UC. Ancient Historical Scripture and Color Vision. Color Research and Application [http://wwwgeocitiescom/das00m/AncientHistScriptColVispdf] 2007;32(4):332-3. Vuilleumier P. How brains beware: neural mechanisms of emotional attention. Trends Cognit Sci 2005;9(12):585-94.

Vuilleumier P, Armony JL, Driver J, Dolan RJ. Effects of attention and emotion on face processing in the human brain: an event-related fMRI study. Neuron 2001;30(3):829-41.

Vuilleumier P, Driver J. Modulation of visual processing by attention and emotion: windows on causal interactions between human brain regions. Phil Trans Roy Soc Lond B Biol Sci 2007;362(1481):837-55.

Wager TD, Jonides J, Reading S. Neuroimaging studies of shifting attention: a meta-analysis. NeuroImage 2004;22(4):1679-93.

Wandell BA. Computational neuroimaging of human visual cortex. Annu Rev Neurosci 1999;22:145-73. 
Whitehead AN. Process and Reality. An Essay in Cosmology. New York-London: The Free Press. A division of Macmillan Publishing Co., Inc.-Collier Macmillan Publishers, 1929. Corrected edition [1978]

Wilson HR, McFarlane DK, Phillips GC. Spatial frequency tuning of orientation selective units estimated by oblique masking. Vision Research 1983;23(9):873-82.

Wojciulik E, Kanwisher N, Driver J. Covert visual attention modulates face-specific activity in the human fusiform gyrus: fMRI study. J Neurophysiol 1998;79:1574-8.

Wylie GR, Javitt DC, Foxe JJ. Task switching: a high-density electrical mapping study. NeuroImage 2003;20(4):2322-42.

Wyvell CL, Berridge KC. Intra-accumbens amphetamine increases the conditioned incentive salience of sucrose reward: enhancement of reward "wanting" without enhanced "liking" or response reinforcement. J Neurosci 2000;20:8122-30.

Yim CY, Mogenson GJ. Response of nucleus accumbens neurons to amygdala stimulation and its modification by dopamine. Brain Res 1982;239:401-15.

Yingling CD, Skinner JE. Gating of thalamic input to cerebral cortex by nucleus reticularis thalami. Attention, voluntary contraction and event-related potentials. Progr Clin Neurophysiol 1977;1:70-96.

Young AW. Face recognition impairments. Phil Trans Roy Soc London 1992;B335:47-54.

Young AW. Face and mind. Oxford: Oxford University Press, 1998.

Young AW, Bruce V. Perceptual categories and the computation of grandmother. Eur J Cognit Psychol 1991;3:5-49.

Young AW, McWeeny KH, Hay DC, Ellis HD. Matching familiar and unfamiliar faces on identity and expression. Psychol Res 1986;48:63-8. 